\title{
ANALISIS KELAYAKAN LOKASI BUDIDAYA RUMPUT LAUT DI PERAIRAN TELUK DODINGA KABUPATEN HALMAHERA BARAT
}

(Feasibility Study on Seaweed Culture Locations in Dodinga Bay, West Halmahera Regency)

\author{
Adnan Sj. Wantasen ${ }^{1}$ dan Tamrin ${ }^{2}$ \\ ${ }^{1}$ Fakultas Perikanan dan Ilmu Kelautan Universitas Sam Ratulangi, Manado, Sulawesi Utara \\ ${ }^{2}$ Fakultas Perikanan dan Ilmu Kelautan Universitas Khairun, Ternate
}

\begin{abstract}
The study was aimed at knowing the feasibility of the waters of Dodinga Bay for seaweed: Kappaphycus alvarezii culture development. The study used a survey method covering aquatic physical, chemical and biological parameters. Result showed that physical, chemical and biologicałparameters fulfilled the criteria for the seaweed growth. Based on the suitability of the water used in this study, Dodinga Bay waters was categorized as S-2 class or having median suitability criteria, i.e. the water possessed moderate threshold for seaweed culture or had animal effect on the aquatic environmental quality, and could still be utilized for seaweed culture development under several technical prerequisites.
\end{abstract}

Keywords: Kappaphycus alvarezii, seaweed culture development.

Penelitian ini bertujuan untuk mengetahui kelayakan perairan untrúk pengembangan budidaya rumput laut Kappaphycus alvarezii di Pantai Dodinga. Penelitian ini menggunakan metode survei meliputi parameter fisik, kimia dan biologi perairan. Hasil penetitian menunjukkan bahwa parameter fisik, kimia dan biologi memenuhi kriteria untuk pertumbuhan rumput laut. Berdasarkan kesesuaian air yang digunakan dalam penelitian ini, perairan Teluk Dodinga dikategorikan kelas S-2 atau memiliki kriteria kesesuaian median, yaitu perairan yang memiliki batas. moderat untuk budidaya rumput laut atau kurang berpengaruh pada kualitas lingkungan air, dât masih bisa dimanfaatkan untuk pengembangan budidaya rumput laut di bawah beberapa prasyaratteknis.

Kata kunci: Kappaphycus alvarezii, pengembanganobudidaya rumput laut.

\section{PENDAHULUAN}

Kawasan perairan Malukt Útara merupakan kawasan yang potensialuntuk pengembangan budidaya rumput lauf, beberapa di antaranya adalah perairan Morotai Selatan, Kepulauan di Guraici dan Kayoa, Taliabu Barat, Perairan Oba dan peratran pesisir Kabupaten Halmahera Barat (éSil Kie Raha, 2010). Teluk Dodinga merupakan kawasan perairan di Kabupaten Halmahera Barat yang menjadi tempat tumbuh alami beberapa jenis rumput laut ${ }^{\circ}$ seperti Kappaphycus alvarezii dan Glacilaria spp. Permasalahan yang terdapat pada kawasan budidaya Teluk Dodinga adalah ketidaksesuaian lahan dan daya dukung, kualitas sumberdaya manusia yang rendah, teknologi budidaya yang masih sederhana dan bibit unggul untuk budidaya rumput laut yang belum banyak tersedia (Bappeda, 2009).

Aktivitas budidaya rumput laut pada kawasan perairan ini masih terbatas pada sistem tradisional dan tidak berkelanjutan sehingga masih menimbulkan permasalahan dalam proses pembudidayaan rumput laut. Hal ini juga belum mencakup prinsip pengelolaan sumberdaya yang baik sehingga hal pertama yang perlu dibuat adalah suatu kajian kelayakan yang berhubungan dengan kualitas lingkungan perairan dalam upaya pengembangan budidaya rumput laut di kawasan Teluk Dodinga.

\section{METODE PENELITIAN}

\section{Metode dan Prosedur Pengambilan Data}

Data yang diperoleh berasal dari data primer yaitu data kualitas perairan, kondisi biofisik perairan Teluk Dodinga ini dijadikan acuan dalam menentukan kriteria kelayakan lahan untuk budidaya rumput laut. Ada lima lokasi atau stasiun pengamatan yaitu Desa Akelaha, Dodinga, Tuguraci, Biamahi dan Sidangolidehe yang diharapkan mewakili habitat perairan Teluk Dodinga. Pengambilan sampel kualitas perairan dilakukan sebanyak 4 kali dengan periode pengambilan setiap dua minggu pada saat pasang dan surut. Metode pengambilan sampel air dan analisisnya mengacu pada 
APHA (1989) seperti yang diperlihatkan pada Tabel 1.

Tabel 1. Parameter dan Metode Analisis pada Pengukuran Kualitas Air di Perairan Teluk Dodinga.

\begin{tabular}{|c|c|c|c|}
\hline Parameter & Safuan & Mat Metode & Keterangan \\
\hline \multicolumn{4}{|l|}{ Fivika } \\
\hline Kecerahan & $\mathbf{m}$ & Secchi disk. visual & In sinu \\
\hline Suhe & ${ }^{4} \mathrm{C}$ & Thermonacter & ln situ \\
\hline Kecepatan arus & can det & Current acter & In simu \\
\hline Pacang sarut & $\mathrm{m}$ & Tengkat berikala & In sinu \\
\hline Kedalaman perairan & m & Tali & In situ \\
\hline \multicolumn{4}{|l|}{ Kimia } \\
\hline $\mathrm{pH}$ & & pH meter, ckltromactrik & In situ \\
\hline Salinitas & 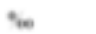 & Refractometer & In situ \\
\hline Oksipen terlarut & $\operatorname{me} 1$ & DO meter & In sinu \\
\hline Nitrat & $\operatorname{mel} 1$ & Speltrofotometer & Laboratorium \\
\hline Phospat & $\operatorname{me} 1$ & Spektrofotomacter & I aboratorium \\
\hline
\end{tabular}

\section{Analisis Data}

Kriteria kelayakan lahan budidaya rumput laut menggunakan data kondisi biofisik perairan Teluk Dodinga dengan mengacu pada ketentuan Standar Nasional Indonesia (SNI) yang dikeluarkan oleh Badan Standar Nasional Indonesia (BSNI) dan Direktorat Standarisasi dan Akreditasi Direktorat Jenderal Pengolahan dan Pemasaran Hasil Perikanan Kementerian Kelautan dan Perikanan Republik Indonesia (Tabel 2). Kriteria ini berlaku untuk semua jenis rumput laut yang dibudidayakan. Kelayak an antara setiap lokasi dibagi dalam tiga klasifikasi yaitu kelayakan tinggi, sedang dan ren dah. Pembagian klaster kesesuaian yang dinitai dari hasil pengukuran dan pengamatan parameter fisika-kimia sebagai berikut (BSN KKP):

1. Kelas S-1, perairan dengan Kelayakan tinggi dan tidak mempunyą pembatas yang berat untuk budidaya runput laut, kalaupun ada pembatas tidak akan memberikan pengaruh nyata bagi perairan, sehingga level ini sangat baik untuk lokasi pembudidayaan rumput laut.

2. Kelas S-2 kelayakan sedang dimana perairan memillki faktor pembatas yang sedang untuk budidaya rumput laut atau lokasi memiliki kondisi yang sedikit berperigarún terhadap budidaya rumput laut, tetapi budidaya masih dapat dilakukan dengan beberapa persyaratan yang sudah dipenuhi.

3. Kelas S-3, memiliki kelayakan yang rendah di mana perairan memiliki faktor pembatas yang kuat untuk budidaya rumput laut sehingga sangat berpengaruh terhadap kualitas perairan. Kondisi ini tidak memungkinkan untuk pengembangan budidaya rumput laut.
Tabel 2. Kriteria Kelayakan Lingkungan Perairan untuk Lokasi Budidaya Rumput Laut sesuai dengan Nilai BSNI dan SNI KKP No. SNI 01-6492-2010.

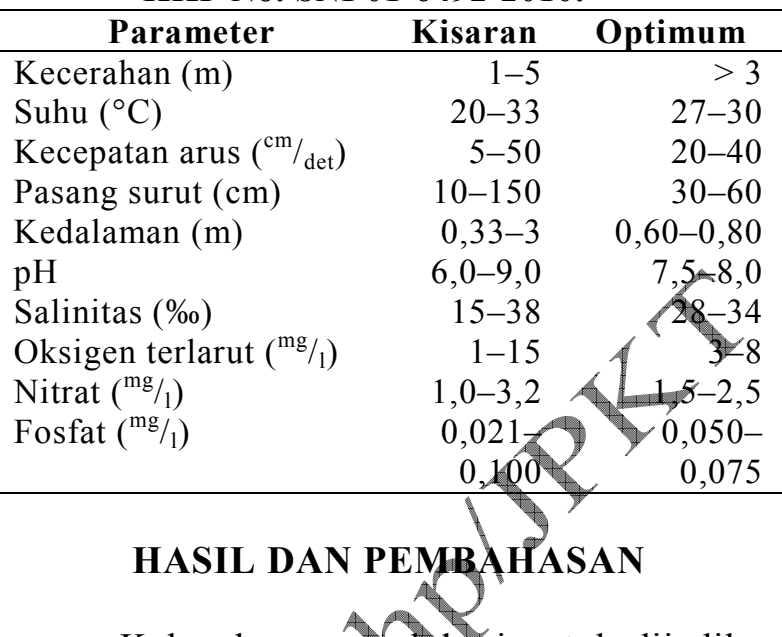

Kelayakan suatu tokăsi untuk dijadikan sebagai area budidaya rumput laut perlu memperhatikan aspek fisika-kimia suatu perairan. Hasil pengukuran parameter kualitas perairan di lokasi penelifian dibandingkan dengan kriteria kisaran kessesuaian.

Nilai parameter fisika-kimia untuk Desa Akefaba umumnya tidak berada pada kisaran fang tidak optimum untuk budidaya rumput laut. Walaupun demikian lokasi ini memiliki toberapa nilai yang berada pada kisaran layak dalam mendukung budidaya rumput laut, kecuali kadar nitrat dan fosfat yang berada pada kisaran tidak layak untuk pertumbuhan rumput laut (Tabel 3).

Tabel 3. Kisaran Nilai Parameter Fisika-Kimia Pada Desa Akelaha.

\begin{tabular}{lrr}
\hline \multicolumn{1}{c}{ Parameter } & \multicolumn{1}{c}{ Kisaran } & Optimum \\
\hline Kecerahan $(\mathrm{m})$ & $2,1-2,75$ & $>3$ \\
Suhu $\left({ }^{\circ} \mathrm{C}\right)$ & $28,3-31,4$ & $27-30$ \\
Kecepatan arus $\left({ }^{\mathrm{cm}} / \mathrm{det}\right)$ & $4,0-30,7$ & $20-40$ \\
Kedalaman $(\mathrm{m})$ & $2,1-2,75$ & $0,60-0,80$ \\
$\mathrm{pH}$ & $6,21-8$ & $7,5-8$ \\
Salinitas $(\%)$ & $30-31$ & $28-34$ \\
Oksigen terlarut $\left({ }^{\mathrm{mg}} / \mathrm{l}\right)$ & $4,2-11,1$ & $3-8$ \\
Nitrat $(\mathrm{mg} / 1)$ & $0,01-1,28$ & $1,5-2,5$ \\
Fosfat $(\mathrm{mg} / 1)$ & $0,09-0,24$ & $0,05-0,075$ \\
\hline
\end{tabular}

Untuk Desa Dodinga umumnya berada pada kisaran nilai yang layak untuk budidaya rumput laut walaupun bukan merupakan nilai yang optimum. Kadar salinitas dan fosfat pada lokasi ini memiliki nilai optimum untuk budidaya rumput laut (Tabel 4).

Pada Desa Tuguraci, semua nilai parameter berada pada kisaran nilai yang tidak op- 
timum, namun berada pada kisaran yang layak untuk budidaya rumput laut (Tabel 5).

Tabel 4. Kisaran Nilai Parameter Fisika-Kimia Pada Desa Dodinga.

\begin{tabular}{lrr}
\hline \multicolumn{1}{c}{ Parameter } & \multicolumn{1}{c}{ Kisaran } & \multicolumn{1}{c}{ Optimum } \\
\hline Kecerahan $(\mathrm{m})$ & $0,70-1,50$ & $>3$ \\
Suhu $\left({ }^{\circ} \mathrm{C}\right)$ & $28,7-32,7$ & $27-30$ \\
Kecepatan arus $\left({ }^{\mathrm{cm}} / \mathrm{det}\right)$ & $3,31-32,8$ & $20-40$ \\
Kedalaman $(\mathrm{m})$ & $0,7-1,50$ & $0,60-0,80$ \\
$\mathrm{pH}$ & $6,20-7,9$ & $7,5-8$ \\
Salinitas $(\%)$ & $30-31$ & $28-34$ \\
Oksigen terlarut $\left({ }^{\mathrm{mg}} / \mathrm{l}\right)$ & $3,1-11,1$ & $3-8$ \\
Nitrat $\left({ }^{\mathrm{mg}} / \mathrm{l}\right)$ & $0,01-1,95$ & $1,5-2,5$ \\
Fosfat $(\mathrm{mg} / \mathrm{l})$ & $0,09-0,20$ & $0,05-0,075$ \\
\hline
\end{tabular}

Tabel 5. Kisaran Nilai Parameter Fisika-Kimia Pada Desa Tuguraci.

\begin{tabular}{lrr}
\hline \multicolumn{1}{c}{ Parameter } & \multicolumn{1}{c}{ Kisaran } & Optimum \\
\hline Kecerahan $(\mathrm{m})$ & $0,50-1,95$ & $>3$ \\
Suhu $\left({ }^{\circ} \mathrm{C}\right)$ & $28,9-33,2$ & $27-30$ \\
Kecepatan arus $\left({ }^{\mathrm{cm} / \mathrm{det}}\right)$ & $3,21-31,7$ & $20-40$ \\
Kedalaman $(\mathrm{m})$ & $0,5-1,95$ & $0,60-0,80$ \\
$\mathrm{pH}$ & $6,52-8,27$ & $7,5-8$ \\
Salinitas $(\%)$ & $30-32$ & $28-34$ \\
Oksigen terlarut $\left({ }^{\mathrm{mg} / 1}\right)$ & $5,2-8,6$ & $3-8$ \\
Nitrat $(\mathrm{mg} / \mathrm{l})$ & $0,01-1,29$ & $1,5-2,5$ \\
Fosfat $(\mathrm{mg} / \mathrm{l})$ & $0,09-0,17$ & $0,05-0,075$ \\
\hline
\end{tabular}

Kisaran nilai parameter fisika-kimia perairan untuk Desa Biamahi pada umumnya layak untuk budidaya rumput laut, walaupun tidak berada pada kisaran nilai yang optimum. Hanya salinitas dan fosfat yang berada pada kisaran yang optimum untuk pertumbuhare rumput laut pada lokasi ini (Tabel 6) Untuk Desa Sidangolidehe memiliki nilai parameter yang berada pada kisaran layak untuk budidaya rumput laut namun tidak memilliki nilai yang optimum untuk budidaya (Tabel-7).

Tabel 6. Kisaran Nilat Parameter Fisika-Kimia Pada Desa Biamahi.

\begin{tabular}{|c|c|c|}
\hline Parametex y & Kisaran & Optimum \\
\hline Kecerahan (m) & $0,73-1,50$ & $>3$ \\
\hline Suhu $\left({ }^{\circ} \mathrm{C}\right.$ & $28,3-33,0$ & $27-30$ \\
\hline Kecepatanarus $(\mathrm{cm} / \mathrm{det})$ & $3,24-34,6$ & $20-40$ \\
\hline Kedalarnan (m) & $0,73-1,50$ & $0,60-0,80$ \\
\hline & $6,35-8,0$ & $7,5-8$ \\
\hline Salmitas (\%o) & $29-32$ & $28-34$ \\
\hline Oksigen terlarut $(\mathrm{mg} / \mathrm{l})$ & $5,0-11,6$ & $3-8$ \\
\hline Nitrat $(\mathrm{mg} / \mathrm{l})$ & $0,06-2,24$ & $1,5-2,5$ \\
\hline Fosfat $(\mathrm{mg} / 1)$ & $0,09-0,22$ & $0,05-0,075$ \\
\hline
\end{tabular}

Hasil analisis parameter fisika-kimia perairan untuk semua lokasi menunjukkan bahwa lokasi Desa Biamahi, paling sesuai dan layak untuk budidaya rumput laut diikuti secara berurut oleh Desa Biamahi, Dodinga, Akelaha dan Sidangolidehe.

Tabel 7. Kisaran Nilai Parameter Fisika-Kimia Pada Desa Sidangolidehe.

\begin{tabular}{lrr}
\hline \multicolumn{1}{c}{ Parameter } & \multicolumn{1}{c}{ Kisaran } & \multicolumn{1}{c}{ Optimum } \\
\hline Kecerahan $(\mathrm{m})$ & $0,90-1,50$ & $>3$ \\
Suhu $\left({ }^{\circ} \mathrm{C}\right)$ & $29,5-34,5$ & $27-30$ \\
Kecepatan arus $\left({ }^{\mathrm{cm}} / \mathrm{det}\right)$ & $2,70-35,0$ & $20-40$ \\
Kedalaman $(\mathrm{m})$ & $0,90-1,50$ & $0,60-0,80$ \\
$\mathrm{pH}$ & $6,36-7,92$ & $7,5-8$ \\
Salinitas $(\%)$ & $30-35$ & $28-34$ \\
Oksigen terlarut $(\mathrm{mg} / \mathrm{l})$ & $4,9-10,6$ & $3-8$ \\
Nitrat $\left({ }^{\mathrm{mg}} / \mathrm{l}\right)$ & $0,01-2,26$ & $1,5-2,5$ \\
Fosfat $(\mathrm{mg} / 1)$ & $0,09-0,59$ & $0,05-0,075$ \\
\hline
\end{tabular}

Tabel 8. Kisaran Nilai Parameter Eisika-Kimia Pada Semua Stasiun di Perairan Teluk Dodinga

\begin{tabular}{lrr}
\multicolumn{1}{c}{ Parameter } & \multicolumn{1}{c}{ Kisaran } & Optimum \\
\hline Kecerahan $(\mathrm{m})$ & $0,73-2,75$ & $>3$ \\
Suhu $\left({ }^{\circ} \mathrm{C}\right)$ & $28,3-34,5$ & $27-30$ \\
Kecepatan arus $(\mathrm{cm} / \mathrm{det})$ & $3,35-35,0$ & $20-40$ \\
Kedalaman $(\mathrm{m})$ & $0,73-2,75$ & $0,60-0,80$ \\
$\mathrm{pH}$ & $6,20-8,27$ & $7,5-8$ \\
Salinitas (\%o) & $29-35$ & $28-34$ \\
Oksigen terlarut $(\mathrm{mg} / \mathrm{l})$ & $3,1-11,6$ & $3-8$ \\
Nitrat $(\mathrm{mg} / \mathrm{1})$ & $0,01-2,26$ & $1,5-2,5$ \\
Fosfat $(\mathrm{mg} / \mathrm{l})$ & $0,09-0,59$ & $0,05-0,075$ \\
\hline
\end{tabular}

\section{3}

Secara umum dapat dijelaskan bahwa hanya ada beberapa nilai parameter fisika-kimia perairan yang terukur di perairan Teluk Dodinga masuk pada kisaran untuk budidaya rumput laut seperti kedalaman, $\mathrm{pH}$, salinitas dan oksigen terlarut (Tabel 8). Kisaran nilai fosfat berada pada $0,09-0,59 \mathrm{mg} / 1$ dan dalam penelitian ini berfluktuasi berada pada kelompok perairan oligotropik dan sebagian mesotropik untuk Desa Akelaha, Dodinga dan Tuguraci sedangkan untuk Desa Biamahi dan Sidongolidehe termasuk dalam kelompok eutropik. Perbedaan nilai ini karena Desa Akelaha, Dodinga dan Tuguraci berada dekat dengan daratan sehingga kawasan ini mendapat cukup banyak aliran unsur hara seperti fosfor, sedangkan Desa Biamahi dan Sidongolidehe berada cukup jauh dari daratan. Sebagai perbandingan kadar unsur fosfor di perairan Kepulauan Seribu yaitu 0,011-0,020 mg/1 (Yusron, 2001), kadar fosfat di Teluk Lhokseudu Aceh berkisar 0,005-0,118 mg/1 (Syahputra, 2005) dan kadar fosfat di Teluk Lampung berkisar antara 0,226-1,065 mg/1 (Wahyuningrum, 2001). Perairan oligotrofik memiliki kadar orthofosfat 0,003-0,01 mg/, perairan mesotrofik memiliki kadar orthofosfat $0,011-0,03 \mathrm{mg} / 1$ dan perairan eutrofik memiliki 
kadar orthofosfat $0,031-0,1 \mathrm{mg} / 1$ (Vollenweider dalam Effendi, 2003)

Berdasarkan kelas kesesuaian perairan yang digunakan, maka perairan Teluk Dodinga dikategorikan sebagai perairan kelas S-2 atau mempunyai kriteria kelayakan sedang (median), yaitu perairan yang mempunyai beberapa faktor pembatas yang kurang sesuai untuk budidaya rumput laut, ataupun memiliki faktor pembatas yang berpengaruh terhadap kualitas lingkungan perairan. Namun demikian kondisi lingkungan perairan ini masih dapat digunakan untuk pengembangan budidaya rumput laut dengan beberapa persyaratan teknis yang harus dipenuhi misalnya sistem budidaya ataupun jenis rumput laut yang dibudidaya harus sesuai kondisi lingkungan perairan (Vollenweider dalam Kankan, 2006)

\section{KESIMPULAN}

Perairan Teluk Dodinga memiliki nilai parameter fisika-kimia yang cukup layak sebagai kawasan pengembangan budidaya rumput laut. Lokasi yang paling sesuai adalah Desa Biamahu, sedangkan untuk kelas kelayakan tergolong sedang. Dengan demikian, hasil penelitian ini menyatakan bahwa kondisi sebagian besar perairan Teluk Dodinga Kecamatan Jaiłolo Selatan, Kabupaten Halmahera Barat meme nuhi persyaratan untuk dilakukan pembudidayaan rumput laut jenis Kappaphycus alvarezî.

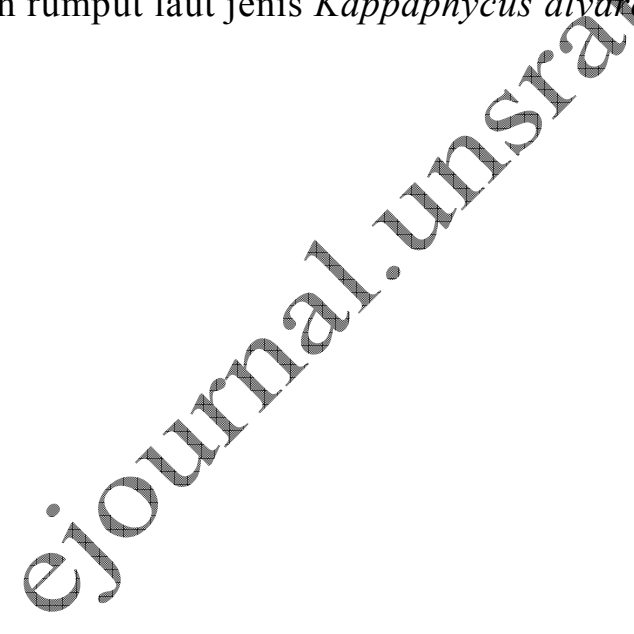

\section{SARAN}

Karena kawasan perairan Teluk Dodinga memiliki beberapa pelabuhan yang berpeluang besar mengalami pencemaran, maka sebaiknya ada kajian mengenai status kontaminasi organotin yang dapat mempengaruhi kawasan tersebut.

\section{DAFTAR PUSTAKA}

American Public Health Asssociation (APXA). 1989. Standard Methods for The Examination of Water and Waste Water Including Bottom Sediment and Sludges. 17th ed. Amer. Publ. Health Association Inc. New York.

Bappeda. 2009. Laporan Kegiatan Pengembangan Kawasan Pesisir Kabupaten Halmahefa Barat. 174 hal.

eLSiL, Kie Raha. 2010. Lapøran Rendampingan Masyarakat Pesisir Teluk Dodinga, Jailolo Selatan. Halmahera Barat. Project USALD UNDP-BAPPENAS RI Jakarta.

Effendi H. 2003. Telaah Kualitas Air Bagi Pengelolaan Sumberdaya dan Lìngkungan Perairan. Penerbit Kanisius. Yogjakarth, 258 hal.

Kankan A. Leonidas. 2006. Penentuan Lokasi Untuk Pengembangan Budidaya Laut Berdasarkan Parameter Fisika Kimia dan Biologi di Teluk Kupang, Nusa Tenggara Timur. Thesis Pascasarjana Universitas Diponegoro, Semarang. 129 hal.

Syahputra Y. 2005. Pertumbuhan dan Kandungan Karaginan Budidaya Rumput Laut Eucheuma cottonii pada Kondisi Lingkungan yang Berbeda dan Perlakuan Jarak Tanam di Teluk Lhokseudu. Thesis Pascasarjana IPB, Bogor. 91 hal.

Yusron M. 2005. Penilaian Kualitas Perairan dan Studi Kelayakan Budidaya Rumput Laut Kappaphycus alvarezii di Beberapa Pulau di Kepulauan Seribu, Teluk Jakarta. Skripsi. IPB, Bogor. 48 hal.

Wahyuningrum PI. 2001. Studi Evaluasi Kesesuaian Wilayah Perairan Teluk Lampung Untuk Budidaya Rumput Laut Eucheuma dengan Pemanfaatan Inderaja dan SIG. IPB, Bogor.102 hal. 


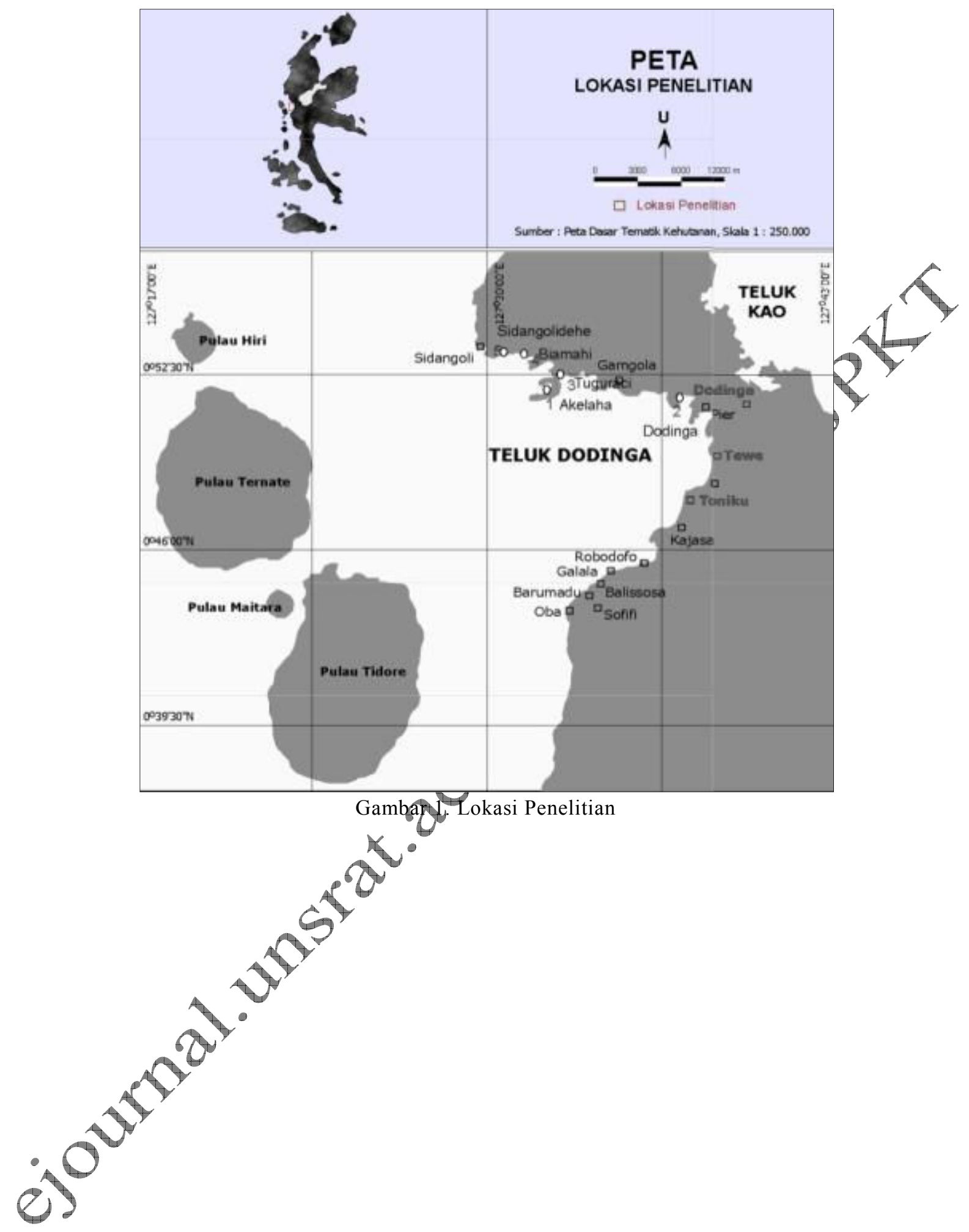

